\title{
Life Experience of Women with Obstetric Fistula in Togo
}

\author{
Ameyo Ayoko Ketevi1 ${ }^{*}$, Dede Regine Diane Ajavon², Baguilane Douaguibe1, Akila Bassowa3, \\ Carmelle Schola Assogba ${ }^{1}$, Assiaham Walawita Tenete ${ }^{1}$, Nagbe Massogblé Kodjo Koffi ${ }^{1}$, \\ Kodjo Fiagnon', Abdoul-Samadou Aboubakari' ${ }^{4}$, Koffi Akpadza1
}

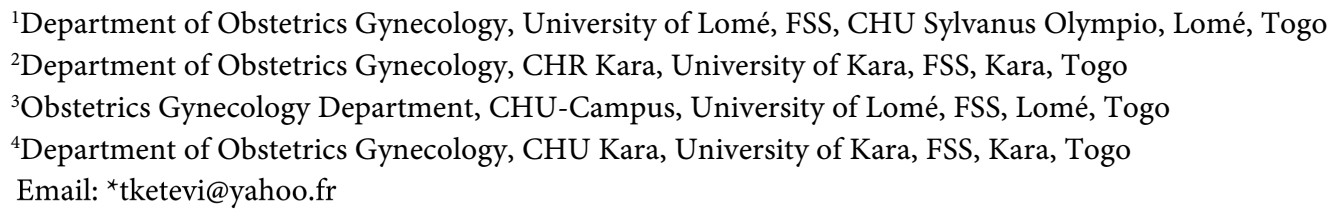

How to cite this paper: Ketevi, A.A., Ajavon, D.R.D., Douaguibe, B., Bassowa, A., Assogba, C.S., Tenete, A.W., Koffi, N.M.K., Fiagnon, K., Aboubakari, A.-S. and Akpadza, K. (2021) Life Experience of Women with Obstetric Fistula in Togo. Open Access Library Journal, 8: e6968.

https://doi.org/10.4236/oalib.1106968

Received: November 8, 2020

Accepted: March 27, 2021

Published: March 30, 2021

Copyright $\odot 2021$ by author(s) and Open Access Library Inc.

This work is licensed under the Creative Commons Attribution International License (CC BY 4.0).

http://creativecommons.org/licenses/by/4.0/ (c) $\underset{\mathrm{BY}}{\text { (i) Open Access }}$

\begin{abstract}
Introduction: Obstetric Fistula (OF) is an abnormal communication between the bladder and the vagina or between the rectum and the vagina and or both. The objective was to describe the experience of OF by the victims. Methodology: The gynecology-obstetrics clinic of the CHU Sylvanus Olympio in Lomé served as the framework for this study. This was a descriptive cross-sectional study, which took place from February 28 to March 19, 2011. Results: A total of 76 women with OF were interviewed. Mothers were more attentive to the problems of women with OF (38.2\%). More than half of women with OF (53.9\%) were rejected by non-family circle. The vast majority of them have experienced a change in their sex life (75\%). Before the fistula, $77.6 \%$ had an income-generating activity. The fistula was associated with a vulvar rash (55.3\%). Women with OF (93.4\%) had a permanent need for cleanliness. Conclusion: The pursuit of cleanliness is an important characteristic of women with OF. The latter are often abandoned by their husbands. All this experience leads women with OF to a "social death".
\end{abstract}

\section{Subject Areas \\ Gynecology \& Obstetrics}

\section{Keywords}

Obstetric Fistula, Experience, Togo

\section{Introduction}

Obstetric fistula (OF) is an abnormal communication between the bladder and 
the vagina or between the rectum and the vagina and or both [1]. It appears in the first week after obstructed labor and manifests as a permanent discharge of urine and/or stools from the vaginal cavity [1]. It is a devastating and preventable scourge that strikes millions of young girls and women around the world [1]. According to WHO statistics, out of 1000 women who die from childbirth in developing countries, 10 succumb to OF [2]. The prevalence of symptoms of vaginal fistula is 1 per 1000 women of childbearing age in sub-Saharan Africa [3]. Women with OF are often stigmatized for decades, enduring physical and psychological symptoms in addition to social isolation [4].

In Togo, the MICS4 survey carried out in 2010 noted a prevalence of $0.03 \%$ of obstetric fistulas. According to other estimates, around 150 to 250 new cases occur each year in Togo [5]. Long absent from health programs in many of our countries, the fight against $\mathrm{OF}$ has aroused renewed interest today since the launch of the global campaign against fistula in 2003 by UNFPA [5].

\section{Patients and Methods}

Our work was carried out in the gynecology-obstetrics clinic of the Sylvanus Olympio CHU in Lomé, Togo national reference center. An OF surgery campaign took place there. There is currently no specialized structure for the care of OF in Togo. This is a descriptive cross-sectional study that took place from February 28 to March 19, 2011 (20 days). Women with OF were identified by WILDAF-Togo in collaboration with some NGOs working in the field of health and women's rights, as part of the campaign for the surgical cure of fistulas, initiated by the Family Health Division (DSF) in partnership with UNFPA. The direct interview technique was used for data collection. A pre-established and pre-tested questionnaire was used for data collection, including the interpersonal relationships between the fistula survivor and her family and friends, the sexuality and fertility among women with OF, the socio-economic consequences of OF, the physical signs associated with $\mathrm{OF}$ and victims' psychological experience of OF.

The operational definitions of the concepts used in this study were 1) constant need for cleanliness: heavy use of perfumes, detergent, laundry and body wash several times a day; 2) fatalism: surrender to God, "only death can deliver me from this disease"; 3) self-deprecation: "I am less than a woman, I have become a child again"; 4) feeling of guilt in others: fault of medical personnel; 5) feeling of self-guilt: "I was punished by God for not listening to my parents, I got pregnant very young without being married"; 6) feeling of worthlessness: "I feel useless, I am useless, at my age I am still a burden for my mother because I cannot go out to work, nobody wants me to come and work in her field because as soon as I come, the other employees move away"; 7) Makeshift cloth: pieces of old loincloths.

The data collected was processed by the Sphinx software. Pearson's chi-square test was used for the analysis of proportions. The values were significant if $\mathrm{p}<$ 
0.05. An authorization ref $71 / 2011 / \mathrm{CHU} / \mathrm{DIR} / \mathrm{TG}$ has been obtained from the management of the SO chu. For reasons of confidentiality and accessibility for patients, our interviews took place in an isolated room located in the same ward as their hospital room. The average interview time was 45 minutes per woman. At the start of each interview, the purpose of the study was clarified to all interviewees. Clear, free and informed consent was obtained before the start of the interview.

\section{Results}

\subsection{Relations between the Woman with $\mathrm{OF}$ and Those around Her}

A total of 76 women with OF were interviewed during the survey period.

In $98.7 \%$ of cases, women with OF informed their spouse. The family sympathized in $93.4 \%$ of cases. Women were rejected by their spouse in $46 \%$ of cases. The compassion of the spouses was found in $30.3 \%$, followed by indifference in $23.7 \%$. Mothers were the most attentive to the problems of women with OF $(38.2 \%)$, followed by brothers and sisters in $26.3 \%$. Regarding the reactions of non-family entourage, there was, among other things, rejection in 53.9\%, mockery in $30.3 \%$, stigma in $25 \%$. Regarding the most difficult thing to bear, women with OF cited permanent urine flow in $55.3 \%$, followed by rejection from the husband in $27.6 \%$ and rejection from friends and family in $17.1 \%$.

\subsection{Sexuality and Fertility in the Life of Women with $\mathrm{OF}$}

Women with OF had a change in their sex life $75 \%$ of the time, due to the discomfort caused by the smell and flow of urine, and dyspareunia. Out of the 76 women with OF, 44 or $57.9 \%$, have stopped having sex. Sexual intercourse became irregular for 13 women with OF (17.1\%). For 36 patients (47.4\%), the partners decided of a change in sex life, while in 21 cases $(27.6 \%)$, it was the patients themselves. Eighteen patients $(23.7 \%)$ were able to give birth after the onset of OF. The remaining 58 (76.3\%) could not give birth. Unfortunately, out of the 18 women with OF who gave birth after the onset of the disease, 7 said the disease had worsened.

Economic consequences of OF: before the fistula, $77.6 \%$ had an income generating activity.

Physical consequences of OF: according to the victims, the fistula was associated with a vulvar rash in $55.3 \%$ of cases (Table 1 ).

\subsection{Psychological Experience of OF by the Victims}

In $93.4 \%$ of cases, women with OF had a permanent need for cleanliness (Table 2).

\subsection{Age of Obstetric Fistula before Surgical Treatment}

In $30.3 \%$ of cases, women lived with the fistula between 10 to 19 years, before surgical treatment. The average being 12 years (Figure 1). 
Table 1. Distribution of patients according to the physical signs associated with the fistula.

\begin{tabular}{lcc}
\hline & Number $(\mathrm{n}=76)$ & Percentage \\
\hline Vulvar rash & 42 & 55.3 \\
Itching & 32 & 42.1 \\
Weight loss & 17 & 22.4 \\
Genitalulceration & 16 & 21.1 \\
Dyspareunia & 13 & 17.1 \\
\hline
\end{tabular}

Table 2. Distribution of patients according to the psychological experience of women with OF.

\begin{tabular}{lcc}
\hline & Number $(\mathbf{n}=\mathbf{7 6})$ & Percentage \\
\hline Isolation or self-exclusion & 70 & 92.1 \\
Permanent need for cleanliness & 71 & 93.4 \\
Self devaluation & 65 & 85.2 \\
Fatalism & 23 & 30.3 \\
Fear of remaining sterile & 18 & 23.7 \\
Feeling of guilt about others & 10 & 13.2 \\
Feeling of self-guilt & 01 & 01.3 \\
Feeling of worthlessness & 23 & 30.3
\end{tabular}

\section{Percentage}

35

30

25

20

15

10

5

0

1.3

$<1$
01-4

25

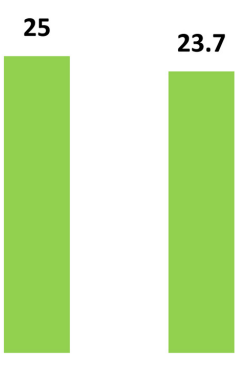

05-9

\section{3}

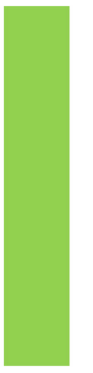

10-19

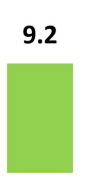

20-29
10.5

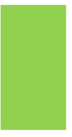

$>30$

Figure 1. Distribution of patients according to the age of the OF.

\subsection{Means of Protection Used by FO Women Carriers}

The makeshift rag alone was used $71.1 \%$ of the time. The makeshift cloth wrapped in plastic, in $13.2 \%$, followed by the commercial trim in $11.8 \%$.

\section{Discussion}

Forty-six percent $(46 \%)$ of women with OF unfortunately reported being rejected by their spouses after the onset of the disease. On the other hand, $30.3 \%$ of them had benefited from their compassion. Another remarkable fact is that almost all the women with OF in our cohort (93.4\%) had benefited from the sup- 
port of their family, especially their mothers (38.2\%). In a similar study conducted in the Central African Republic [6], the authors noted that patients were supported in $56.3 \%$ of cases by their spouses and in $53.9 \%$ of cases by their families. In contrast, in the study carried out by Changole and al in Malawi in 2017 [7], most women were supported by their husbands, who saw themselves as wholly or partly responsible for the disease. Our results are identical to those of Salma al in 2019 [8], where 50\% of spouses divorced their wives after the disease. In fact, in the interpersonal relationships between the woman with OF and those around her, two types of attitudes appeared, being diametrically opposed.

It was about solidarity, strong emotional support from the mother, children, father and brothers and to some extent the spouse on one hand or, and on the other hand, rejection and stigmatization which externalization allowed anathemas and stereotypes to appear in the comments. It was the members of the paternal or maternal family who mobilized their financial and material resources to support the patient with the costs of care. But generally it was the mother who shared her suffering with her daughter. The fistula disease pushed the victim into self-exclusion and seclusion. Indeed, the latter felt ashamed at the constant and unbearable foul odors they gave off. In this situation, only the mother could share the intimacy of her daughter and provide her with multifaceted support, combining moral comfort and assistance in matters of hygiene. On the other hand, the support of the entourage was difficult to acquire according to the victims. Thus, $25 \%$ of our patients declared to be victims of stigmatization, and $30.3 \%$ victims of all kinds of mockery.

These results are lower than those of Barageine and al in 2015 [9], in which almost all women with OF were stigmatized by their close relatives. This could be explained by the fact that, the smell of urine arouses rejection so that the woman carrying OF will not even be able to sell prepared food, as evidenced by the words of this spouse: "Before she sold the local drink (tchoukoutou), but after the onset of the disease, because of the smell that she gave off, no one bought her drink, she had to stop selling to stay at home" (spouse of a female OF carrier, Dankpen).

Sexual abandonment was noted in $57.9 \%$ of our patients. In $47.4 \%$ of cases, they said that it was their spouses who were responsible for these changes in their sexual life. Our results are slightly better than those of Kaboré and al in 2014 [10], who observed after the onset of the fistula that 55 patients (32.4\%) were separated from their partner. Also, for Barageine and al in 2015 [9], the disease negatively affected the sexual life of patients due to the constant flow of urine. The reasons given were mainly spousal rejection, dyspareunia and discomfort with the smell and flow of urine. "It's like I'm on my period." This compromised sexuality would undoubtedly be the basis of the separation of the couple.

In our series, $23.7 \%$ of women with OF declared having given birth after the occurrence of the fistula. These results are superior to those of Sissoko and al in Mali in 2017 [11] that had recorded 6 cases of pregnancy among the 57 women 
with OF. Indeed, motherhood is a strategy that justifies and consolidates matrimonial unions, especially in rural areas where the pro-natalist ideology, which relegates women to a lower social status, justifies and assigns to marriage, an exclusive purpose which is procreation. The fact of not having children belittles a married woman. The mother-in-law and the sisters-in-law exert psychological pressure on the spouse of the sick woman to divorce her or to enter into a polygamous union.

"When I had my illness, I didn't get pregnant anymore. My in-laws then rejected me, they asked my husband to kick me out to take another wife. My husband remarried without repudiating me, but when he died I was kicked out of the house by my mother-in-law and my sisters-in-law" (Widow, 55, Binah).

The loss of income-generating activity is statistically significant in women with OF $(\mathrm{p}<10-5)$. Women reportedly spend all of their time trying to cover up the symptoms of their disease

Two types of pain make the social life of women with OFs unbearable. The first pain is physical. In our series, $55.3 \%$ of our patients complained of vulvar rash, $42.1 \%$ of itching and $17.1 \%$ of dyspareunia. Our results are lower than those of Siborurema in 2006 [12] who reported $42.7 \%$ of dyspareunia cases in its series in Rwanda. Indeed, the humidity created by the permanent flow of urine would promote itching which would force the patient to resort to gestures (scratching the inside of the legs) which are socially condemned in adults, especially women. Also, this painful experience would lead to a behavior of withdrawal or self-exclusion from the assemblies of the members of the community: "I am so ashamed to the point that where everyone sits to chat, I do not go. But if I ever had the audacity to go I would stay behind and pull away very slowly before the meeting was over for fear they would notice me. The urine I was losing was so hot that all my sex hurt." (Female OF Carrier, 50 years old, Dankpen)

The second pain is psychological. Thus, almost all (92.1\%) of our patients were isolated from their entourage. Almost all of them (93.4\%) had a permanent need for cleanliness, $85.2 \%$ of them devalued themselves. For Salma andal in 2019 [8] apart from self-isolation and self-devaluation, patients used smoke baths to disguise the smell of urine or just drank a little water to reduce blood loss urine. This results in a very severe restriction on freedom of movement and attendance to reduce the shame and embarrassment caused by the foul odor given off by the urine that made the loincloth wet. This damage to the body creates a psychological tension triggered by repetitive and routine private part hygiene that absorbs the energy and the time that the woman with fistula would have spent on another activity. This daily experience is said to be at the origin of self-marginalization. If it is difficult to hide the disease from family members, it is possible to avoid sharing a meeting with members of the community. "I no longer go out, I am at home all the time, I do not go to ceremonies or to the market", "and this disease keeps me at home".

The majority of patients had access to surgical care averagely 12 years after the onset of OF in Togo. In Uganda, it is 18 years. The delay between the onset of 
fistula and treatment is an important factor in preventing socio-economic and psychosocial consequences.

\section{Conclusions}

All these behaviors and attitudes put together, combined with the abandonment by the husband, lead the woman victim of fistula to a "social death" ranging from the subtle exclusion from community life to confinement and madness in the worst case. Women with OF have a constant need to maintain a minimum of cleanliness. This search for cleanliness is an important characteristic of these women and is also the sign that allows the community to identify them.

This constant search sometimes borders on obsession, which exhausts them financially and morally and sometimes leads them to an atypical social behavior. Urgency should therefore be assessed at several levels. The fundamental question is how to be able to help the female victim to live with others in a dignified way. This state of affairs calls for an appropriate response, going beyond reconstructive surgery. Actions must be taken both upstream (adequate obstetric care, palliative care and psychosocial support) and downstream (social and economic reintegration and rehabilitation) for these women. Communities should not be left out in the process.

\section{Conflicts of Interest}

The authors declare no conflicts of interest regarding the publication of this paper.

\section{References}

[1] WHO (2009) Obstetric Fistula: Guiding Principles for Clinical Management and Program Development. 4-11.

[2] UNFPA (United Nations Population Fund) Population Council (2013) Obstetric Fistula Study. UNFPA, New York. https://www.unfpa.org

[3] Maheu-Giroux, M., Filippi, V., Samadoulougou, S., Castro, M.C., Maulet, N., Meda, N., et al. (2015) Prevalence of Symptoms of Vaginal Fistula in 19 Sub-Saharan Africa Countries: A Meta-Analysis of National Household Survey Data. The Lancet Global Health, 3, 271-278. https://doi.org/10.1016/S2214-109X(14)70348-1

[4] Siddle, K., Mwambingu, S., Malinga, T. and Fiander, A. (2013) Psychosocial Impact of Obstetric Fistula in Women Presenting for Surgical Care in Tanzania. International Urogynecology Journal, 24, 1215-1220. https://doi.org/10.1007/s00192-012-1994-6

[5] (2017) UNFPA TOGO Fight against Obstetric Fistula in Togo, Restore Smile and Dignity to Women.

[6] UNFPA (2005) Ministry of Health-Central African Republic: Epidemiological and Socio-Anthropological Study of Obstetric Fistulas in the Central African Republics.

[7] Changole, J., Thorsen, V.C. and Kafulafula, U. (2017) I Am a Person But I Am Not a Person": Experiences of Women Living with Obstetric Fistula in the Central Region of Malawi. BMC Pregnancy and Childbirth, 17, 433-446. https://doi.org/10.1186/s12884-017-1604-1

[8] Salma, A.E.A. and Viva, C.T. (2019) "I Feel Myself Incomplete, and I Am Inferior to 
People": Experiences of Sudanese Women Living with Obstetric Fistula in Khartoum, Sudan. Reproductive Health, 16, 183-194.

https://doi.org/10.1186/s12978-019-0846-y

[9] Barageine, J.K., Beyeza-Kashesya, J., Byamugisha, J.K., Tumwesigye, N.M., Almroth, L. and Faxelid, E. (2015) "I Am Alone and Isolated": A Qualitative Study of Experiences of Women Living with Genital Fistula in Uganda. BMC Women's Health, 15, 73. https://doi.org/10.1186/s12905-015-0232-Z

[10] Kaboré, F.A., Kambou, T., Ouattara, A., Zango, B., Yaméogo, C., Kirakoya, B., et al. (2014) Epidemiological, Etiological and Psychosocial Impact of Urogenital Fistulas in a Cohort of 170 Consecutive Patients, Treated in Three Centers in Burkina Faso from 2010 to 2012. Progress in Urology, 24, 526-532. https://doi.org/10.1016/j.purol.2014.03.001

[11] Sissoko, I., Tembely, A.D., Sangare, D., Samassekou, A., Kone, O., Some, D., et al. (2017) Pregnancy after Obstetric Vesico-Vaginal Fistula at the Oasis Center, CHU point Gbamako: About 6 Cases. Uro' Andro, 1, 384-387.

[12] Siborurema, L. (2006) Urogenital Fistulas of Obstetric Origin: Epidemiological, Socioeconomic, Clinical and Therapeutic Aspects at Ruhengeri Hospital, Rwanda. Doctoral Thesis in General Medicine, National University of Rwanda, Butare. 